Notfall Rettungsmed 2009 $\cdot$ 12:301-302 DOI 10.1007/s10049-009-1163-8 Online publiziert: 22. Mai 2009

(c) Springer Medizin Verlag 2009
R. Koeniger ${ }^{1} \cdot$ K. Schneider ${ }^{2}$-G. Nömer ${ }^{3} \cdot$ K.-G. Kanz ${ }^{4}$

${ }^{1}$ Präklinik, Klinikum Bogenhausen, München

${ }^{2}$ Kreisverband München, Bayerisches Rotes Kreuz, München

${ }^{3}$ Rettungszweckverband München

${ }^{4}$ Notarztstandort München Mitte, Chirurgische Klinik, Campus Innenstadt, Klinikum der Universität München

\section{Algorithmus für das präklinische Management bei Verdacht auf Schlaganfall}

\section{Notfall Rettungsmed 2009 • 12:107-108}

In $\bullet$ Abb. 1 des Beitrags ,Algorithmus für das präklinische Management bei Verdacht auf Schlaganfall" sind redaktionelle Fehler enthalten. Zwei Angaben in der Checkliste „Vitale Störung” sind nicht richtig:

- Die Angabe „AF $<10$ oder $>20 / \mathrm{min} ”$ muss korrekt lauten: „AF $<10$ oder $>29$ /min".

- Die Angabe „GCS $>9$ " muss korrekt lauten: „GCS $<9$ ".

Wir bitten um entsprechende Beachtung.

Die Online-Version des Originalartikels finden Sie unter http://dx.doi. org/10.1007/s10049-009-1152-y

\section{Korrespondenzadresse}

PD Dr. K.-G. Kanz

Notarztstandort München Mitte, Chirurgische Klinik, Campus Innenstadt, Klinikum der Universität München Nussbaumstr. 20, 80336 München karl-georg.kanz@med.uni-muenchen.de 


\section{Erratum}

Präklinisches Management bei Verdacht auf Schlaganfall

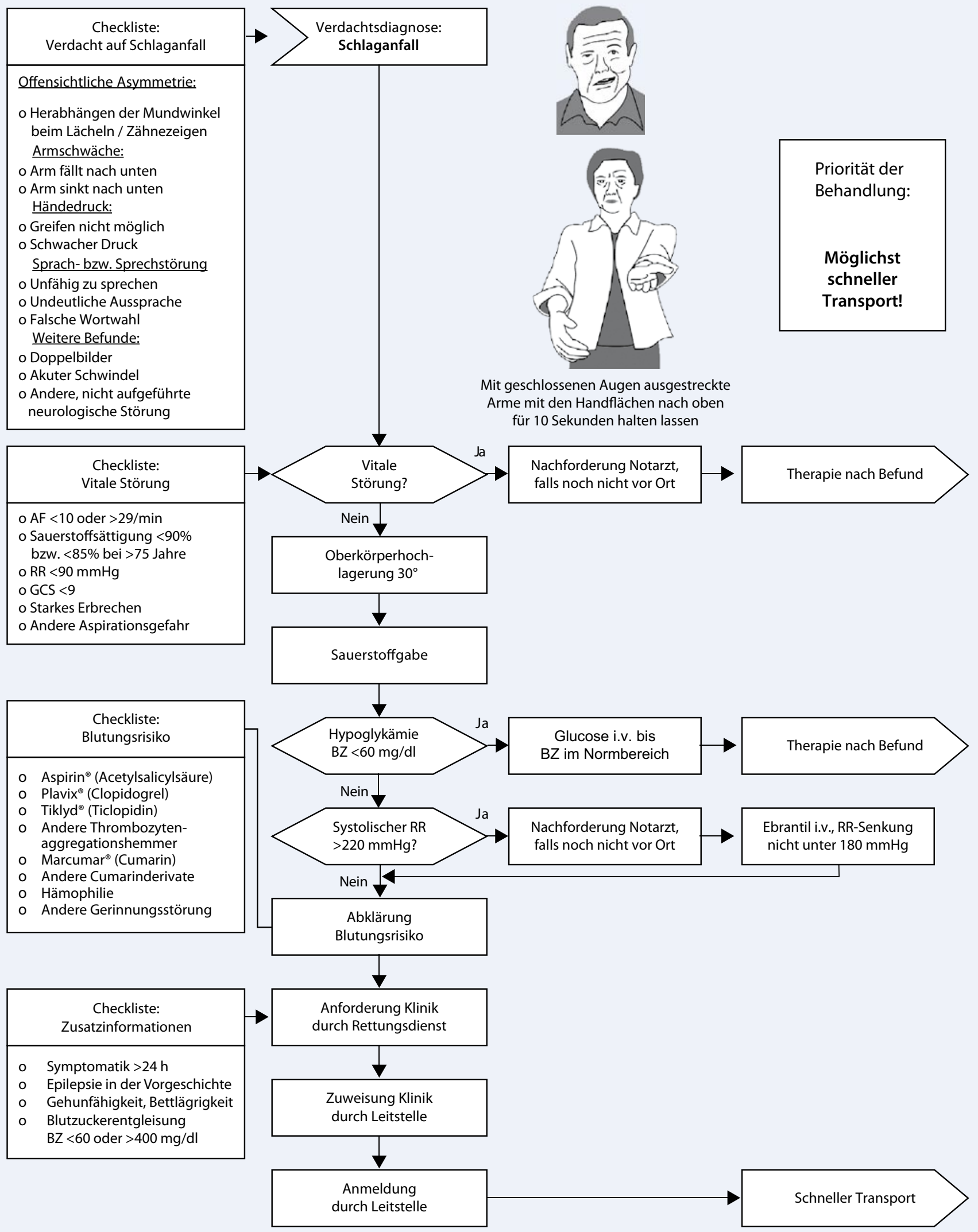

Abb. $1 \Delta$ Algorithmus für das präklinische Management bei Verdacht auf Schlaganfall. AF Atemfrequenz; BZ Blutzuckerspiegel; GCS Glasgow Coma Scale; RR Riva-Rocci 